\title{
Gente inteligente para un patrimonio ingente: el caso de Castilla y León
}

Sobre un amplio territorio, el de Castilla y León, se encuentran abundantes testimonios culturales de la historia de los últimos milenios junto a un patrimonio vivo que depende de poblaciones rurales en constante disminución. La débil ocupación humana de este territorio da relevancia a las iniciativas que se abordan desde las administraciones públicas. La pretensión de salvaguardar ese patrimonio sólo mediante la creación de elementos de atracción turística choca, por un lado, con las propias tendencias reales del turismo y, por otro, con la escasa participación que se da a los habitantes de esas comarcas marginadas.

Antonio Bellido Blanco | Museo de Salamanca

URL de la contribución <www.iaph.es/revistaph/index.php/revistaph/article/view/3855>

La realidad es más cruel de lo que nos gustaría. Castilla y León, con algo menos de dos millones y medio de habitantes, tiene una densidad de población relativamente baja, de $26,23 \mathrm{hab} / \mathrm{km}^{2}$ para su conjunto, aunque con extremos de $8,83 \mathrm{hab} / \mathrm{km}^{2}$ en la provincia de Soria. Además la tendencia general desde hace décadas es a un paulatino y suave descenso en la cantidad de moradores.

Del total de residentes, el $43,5 \%$ vive en las nueve capitales de provincias. En cambio, las localidades con menos de 2.000 habitantes suponen el $94 \%$ de los 2.248 municipios de Castilla y León y sólo el $25,74 \%$ de los habitantes (PLAN, 2016; MOLINA DE LA TORRRE, 2012: 6-8).

Por otro lado está el peso del patrimonio cultural en toda Castilla y León, especialmente en el ámbito rural. Casi cada pueblo cuenta al menos con una iglesia con unas cuantas obras de arte en su interior, alguna ermita, varias casas nobles o de arquitectura tradicional, edificios dedicados a oficios tradicionales como molinos o fraguas y aun pueden vivir personas que recuerden viejos saberes muy diversos sobre labores y trabajos o diversas formas de tradición oral.

La política de desarrollo rural lleva muchos años resaltando el valor de todo ese patrimonio, que se considera un recurso de un alto valor estético e histórico y que reúne el 9,3\% del total de bienes de interés cultural (BIC) españoles (PROGRAMA, 2014: 18).

\section{La realidad del patrimonio en el ámbito rural}

Nadie debe llamarse a engaño. Tal como se entiende hoy la cultura, esta apenas logra relevancia salvo que se la dote de un aprovechamiento turístico. El ámbito rural conserva una gran cantidad de edificios históricos. A ello se suman otros elementos más recientes pero igualmente cargados de significado cultural y de identidad para las poblaciones locales, cuyas raíces además tienen a menudo un origen de tanta o mayor antigüedad: oficios, tareas, tradiciones orales, comportamientos y creencias.

Todo ello constituye una enorme riqueza cultural que sin embargo se dispersa por un amplio territorio donde se produce simultáneamente un importante éxodo de población. La repercusión más clara es la pérdida de mantenimiento de ese patrimonio cultural que en parte cae en una situación de ruina y que también se ve afectado por el olvido que conlleva la muerte de quienes lo conocen y sustentan.

Frente a esta cultura, nos encontramos con que tras la excusa de que el turismo ayuda a conocer, preservar y disfrutar el patrimonio cultural se esconde una estrategia que se vuelca en potenciar una pequeña parcela de todo lo que engloba la cultura. Tras la propaganda de que el turismo contribuye al desarrollo económico, social y cultural de los pueblos florece una realidad mucho más compleja en la que el turismo puede destruir modos de vida, tradiciones y hasta bienes patrimoniales. 
Las administraciones regionales tratan de proteger ese patrimonio mediante el recurso a la declaración de bienes de interés cultural. La consecuencia más clara de este procedimiento es otorgar un reconocimiento a determinados bienes, pero su alcance es relativo desde el momento en que las acciones de protección y mejora que se acometen a continuación dependen en grado sumo de sus propietarios. Estos raras veces suelen contar con los medios adecuados para cumplir las expectativas de la administración, por más que se creen líneas de subvención y crédito.

La creación de normativas urbanísticas que protegen la fisonomía tradicional de los núcleos urbanos, por ejemplo, suele chocar con abundantes obstáculos. Por un lado, está el propio gusto de los vecinos dominado por la afinidad con lo más moderno; por otro, el deseo de sacar el máximo partido de las limitadas parcelas urbanas y de adecuar el espacio a los usos actuales; $y$, finalmente, la mayor facilidad para conseguir y utilizar materiales modernos de construcción.

Otras veces la marcha a las ciudades y la desvinculación producida respecto a los lugares de origen suele conducir a la pérdida de referencias que permitan identificar a los propietarios de los elementos patrimoniales. En un par de generaciones la división de las herencias multiplica el número de personas titulares de los bienes y correlativamente disminuye su valor y el interés por ellos, que quedan olvidados a su suerte.

Por ello no es raro que las casas se arruinen y que edificios más recios, como castillos y palacios, se pongan a la venta en la pretensión de que llegue un inversor que cuente con el dinero suficiente como para emprender las obras necesarias para su rehabilitación. Otros ni siquiera tienen la oportunidad de ser comprados y se pierden poco a poco, casi todos en el ámbito rural, como muestra la lista roja del patrimonio de Hispania Nostra.

En cuanto al patrimonio inmaterial, los conocimientos dejan de enseñarse por considerarse faltos de utilidad para los tiempos actuales o se mezclan con otras tradiciones llegadas desde sitios muy diversos, generando culturas híbridas más ligadas al ámbito urbano que al rural.
Al final, cuando se quiere sacar adelante alguna iniciativa de protección del patrimonio cultural en el ámbito rural, lo más normal es esperar que llegue el apoyo económico de las instituciones. Ya sea a través de subvenciones de la administración regional o provincial o dentro de programas de financiación europea, las cuantías y la extensión temporal siempre son limitadas.

\section{Turismo rural en cifras}

La despoblación de los núcleos históricos ante el avance de los negocios que atienden sólo a los intereses de los turistas son una pequeña evidencia de este fenómeno; la invasión de turistas que los cruceros llevan a Barcelona diariamente es otra muestra. Sin duda el turismo rural se mueve a otra escala, pero el problema existe igualmente. Nada tiene de extraordinaria la visión de esos turistas llegados en sus coches que pasan una hora, o poco más, en cada pueblo en el que paran. En un solo día pueden haber visitado tres o cuatro para retirarse a dormir en una de las capitales de provincia y retomar al día siguiente su peregrinaje cultural.

No debe extrañarnos que en el turismo rural las cifras (ENCUESTA, 2016) sean sensiblemente inferiores a las de otros como el turismo "de sol y playa" y el "cultural". Obviando este detalle, Castilla y León puede presumir de liderar esta categoría en cuando a número de visitantes por encima del resto de comunidades autónomas españolas, entre las que le siguen Cataluña y Asturias. Otro punto que hay que considerar es la escasa duración de las estancias. Mientras a nivel nacional la media es de 2,70 días, en Castilla y León se queda en 2,21 (una de las más bajas, tras Madrid y Galicia) frente a los registros más altos que se logran en Canarias (5,15 días), Baleares (4,19 días), Andalucía (3,36 días) y Asturias (3,26 días). De nuevo se aprecia la debilidad del turismo regional, que parece no superar el límite de un fin de semana.

Un factor más que debe tenerse en cuenta es el de la estacionalidad del turismo rural en Castilla y León. Si se atiende a la procedencia de los viajeros, los españoles tienen su punto álgido en agosto, dándose el mínimo en enero y febrero; mientras que los extranjeros mantienen una mayor homogeneidad temporal, con una mayor 
frecuentación entre mayo y septiembre y una escasa presencia entre noviembre y marzo. Al mismo tiempo, valorando el grado de ocupación de los alojamientos, los mejores periodos coinciden con Semana Santa, julio, agosto y diciembre, y los peores son los meses de enero y febrero. Sin embargo, si se atiende sólo a la ocupación de los fines de semana no se manifiestan significativas diferencias durante el año, salvo por un bajón notable en el mes de enero.

Si se desciende a nivel provincial, se descubre que las que más turistas reciben son -por orden decrecienteÁvila, Segovia, Salamanca, León, Soria y Burgos. Así mismo entre las quince principales zonas de turismo rural sólo una afecta a Castilla y León, el Parque Nacional de Picos de Europa.

\section{El obstáculo de la falta de señas de identidad}

La experiencia demuestra que las intervenciones puntuales a veces logran llamar la atención y despertar gran expectación, pero a medio y largo plazo la mayoría pierden ímpetu, van quedando abandonadas y se diluyen hasta desaparecer. El primer paso es asegurar la conservación del patrimonio cultural, a lo que se suma dotarle de una función educativa y de interpretación. Cada vez que se restaura un monumento, se inaugura un centro de interpretación o un museo, se señaliza una ruta o se abordan tareas de investigación se está abriendo camino a la valorización del patrimonio, al turismo y a la potenciación de elementos de identidad.

La existencia de infraestructuras culturales es esencial, pero de poco valen cuando no están respaldadas por la gente que vive e interviene en el territorio. De esta realidad deriva la actual consideración de los paisajes culturales, como forma de ordenación del territorio sobre el que actúan comunidades enteras. Y en la validez de estas actuaciones es fundamental el factor temporal para asegurar la efectividad de lo planteado.

La labor continua desarrollada por personas como el folklorista zamorano Joaquín Díaz o la etnógrafa leonesa Concha Casado resulta excepcional dentro del panorama general de reactivación del patrimonio cultural, donde abundan las intervenciones puntuales y espo-

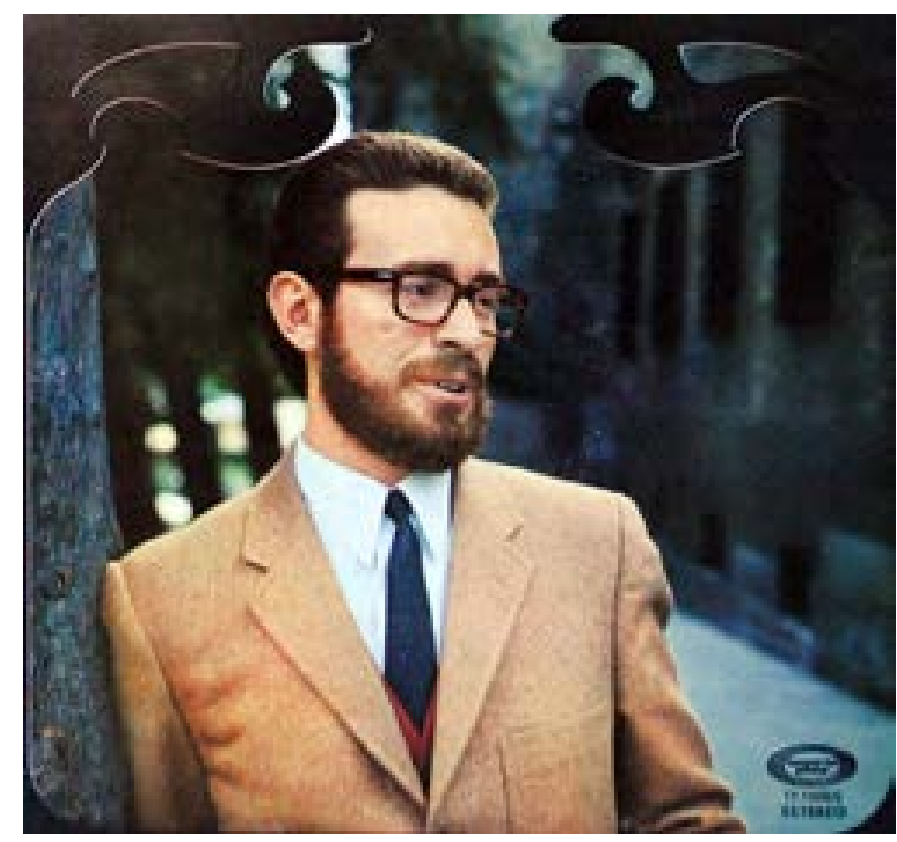

Joaquín Díaz. Portada de su disco De mi álbum de recuerdos (1969)

rádicas. Aquí se incluiría el recuerdo de muchos museos etnográficos inaugurados a finales de los setenta y durante los años ochenta en diversos pueblos sorianos (RUIZ EZQUERRO, 1991), por ejemplo, cuyo funcionamiento dependió de la buena voluntad de los vecinos que se brindaban a atender a los turistas que ocasionalmente se acercaban a los pueblos.

Del mismo modo habría que pensar en los mercados medievales que aparentemente dinamizan diversas localidades sólo durante un fin de semana al año, igual que otros eventos como la reconstrucción de hechos históricos, determinados festivales de música o artes escénicas y ferias gastronómicas. Su éxito reside de modo general en que los eventos de recreación histórica suelen gestionarse con una escasa planificación y no requieren elevados presupuestos mientras que, sin embargo, generan una gran aceptación entre el público (ROJAS RABANEDA, 2011).

La realidad es que en los ámbitos rurales las actividades limitadas a un fin de semana -ni siquiera llegan a ser estacionales- hacen que el nombre del pueblo suene en los oídos de la gente y que salga en la prensa (al menos provincial), pero poco más. Todo dentro de una 


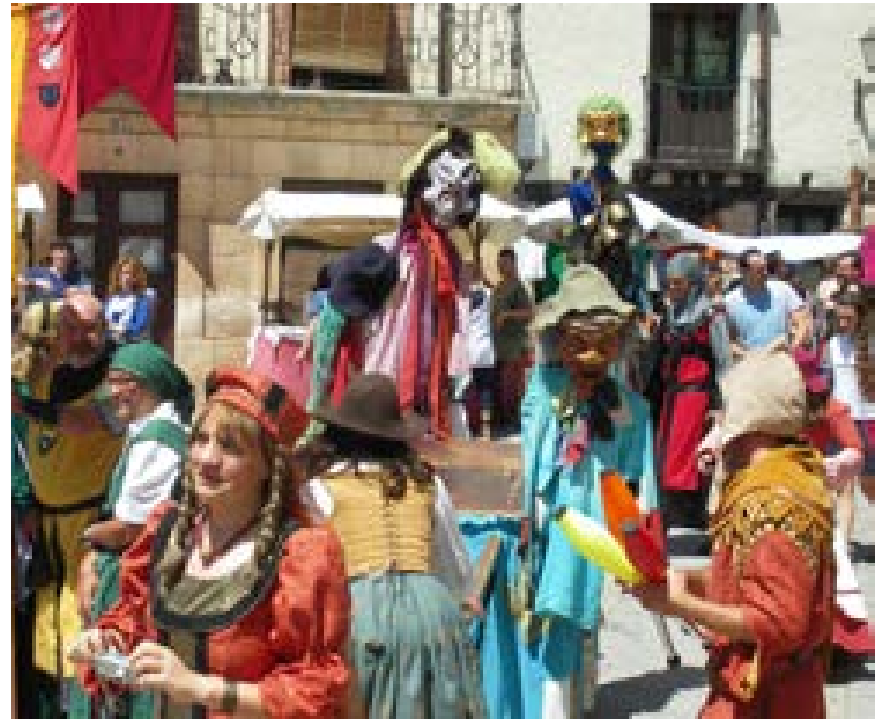

Mercado medieval de Covarrubuas, Burgos, 2012 | foto Luis García Castro

imagen de que estas celebraciones son todas iguales y se copian unas a otras. $Y$ tampoco sirve de mucho centrarse en un sector concreto de la sociedad interesado en un tipo concreto de evento cultural y convertirse en un punto de referencia "insoslayable" para una selecta minoría.

La clave de todas las intervenciones debe residir en la implicación de las personas que viven cotidianamente con ese patrimonio cultural, que son quienes lo susten$\tan$ y aseguran su pervivencia. Así ha ocurrido con todo lo que nos ha llegado y que se ha mantenido durante generaciones. Nadie debe prescindir del elemento humano en aras del relevante papel actual de la tecnología. Lo imprescindible es contar con personas lúcidas que sepan ver la importancia del patrimonio y sean capaces de implicar a otros en su visión. Pero dentro de esos otros no sólo tienen cabida políticos, técnicos, estudiosos o creadores de tendencias, sino que el grupo fundamental debe integrarlo la gente normal que convive y mantiene cada bien patrimonial.

No cabe pensar que todo el espacio rural está abocado inevitablemente al abandono y la despoblación, y que se vaya a convertir en una especie de desierto jalonado por pequeños oasis hasta donde lleguen los viajeros hábilmente manejados por los operadores turísticos. Acaso hoy el tiempo juegue en favor de esa posibilidad, al igual que los modelos culturales dominantes impuestos por los agentes económicos, por ello es tan importante acometer las políticas culturales con inteligencia y sagacidad.

\section{Hacia modelos inteligentes}

Más allá de la obviedad de que las inversiones deben contar con estudios y planificación a largo plazo, es evidente que mucho puede mejorarse. Entre las intervenciones más recientes y significativas desarrolladas sobre el patrimonio cultural de Castilla y León sobresalen los casos de Siega Verde, la explotación de la sal en las lagunas de Villafáfila o la minería del oro en la provincia de Zamora (todas incluidas en el programa de cooperación transfronteriza España-Portugal POCTEP 20072013). Los trabajos de documentación, publicaciones, exposiciones, jornadas técnicas, restauraciones y obras de señalización ¿cómo han incidido sobre el día a día de las gentes y los territorios donde se enclavan esos recursos patrimoniales?

No resulta fácil de evaluar; en parte por la cercanía en la finalización de estos proyectos, pero también porque no existen parámetros para hacerlo. Habría que conocer si se han desarrollado iniciativas empresariales al hilo de la revalorización de estos recursos, si estas han permitido mejorar las condiciones de vida de las localidades aledañas, si ha aumentado la población asentada en la zona o si se han producido incrementos en el flujo de turistas. No podemos decir quién se ocupa de estos aspectos. Falta información sobre detalles que hoy se consideran indispensables como el número de visitantes, su procedencia y su distribución a lo largo del año, los patrones de comportamiento, el impacto de la celebración de eventos específicos o sobre la rentabilidad económica para sus gestores.

Pero incluso atendiendo a instalaciones con una trayectoria más larga, como las aulas arqueológicas y centros de interpretación fundados sobre todo durante los años 90 y el inicio del siglo XXI, los datos no aparecen con facilidad. Ni la Junta de Castilla y León, ni la Fundación del Patrimonio Histórico de Castilla y León -que invirtieron en su creación-, ni los ayuntamientos -que hoy gestionan muchas de estas instalaciones- los proporcionan. 
Faltan estudios previos en la mayoría de las zonas que establezcan la disponibilidad de instalaciones turísticas, como alojamientos y restaurantes, que creen los cauces para la mayor duración de las estancias y el mayor gasto por turista. Tampoco suelen crearse redes turísticas que aúnen los distintos servicios en una misma oferta.

Además parece inevitable reconocer la necesidad de realizar auditorías. Más allá de los datos que pueda proporcionar cada gestor de los elementos patrimoniales es imprescindible conseguir datos que hoy sólo se conocen para grandes urbes. Deberían cuantificarse los ingresos que generan en cada destino los turistas, el gasto diario y por estancia de cada turista, el peso del sector turístico en la economía de cada comarca, los ingresos generados en cada destino por persona ocupada y la temporalidad del trabajo en este sector, por ejemplo. $Y$ por supuesto evaluar la eficacia en lograr asentar población local y en crear nuevas fuentes de trabajo.

La recuperación de elementos patrimoniales no basta. Deben estar marcados unos objetivos que justifiquen las fuertes inversiones que se realizan y deben realizarse seguimientos para valorar su consecución y reelaborarlos conforme pasa el tiempo y las circunstancias se modifican. La inevitable continuidad en los proyectos sólo puede estar asegurada por las personas que viven en el territorio y sólo si se consigue que se identifiquen con la imagen que ese patrimonio transmite.

Que esa gente prefiera utilizar materiales tradicionales en las construcciones, elaborados de forma no-industrial, que se mantengan estructuras y decoraciones alejadas de los modelos urbanitas más actuales, que se recuperen antiguos oficios y tareas, que estén dispuestos a renunciar a la cercanía de infraestructuras educativas o sanitarias para sentirse más cercanos a la tierra y sus raíces, todo eso depende de las actitudes y los sentimientos, no de las inversiones puntuales y las directrices de las administraciones regionales o provinciales.

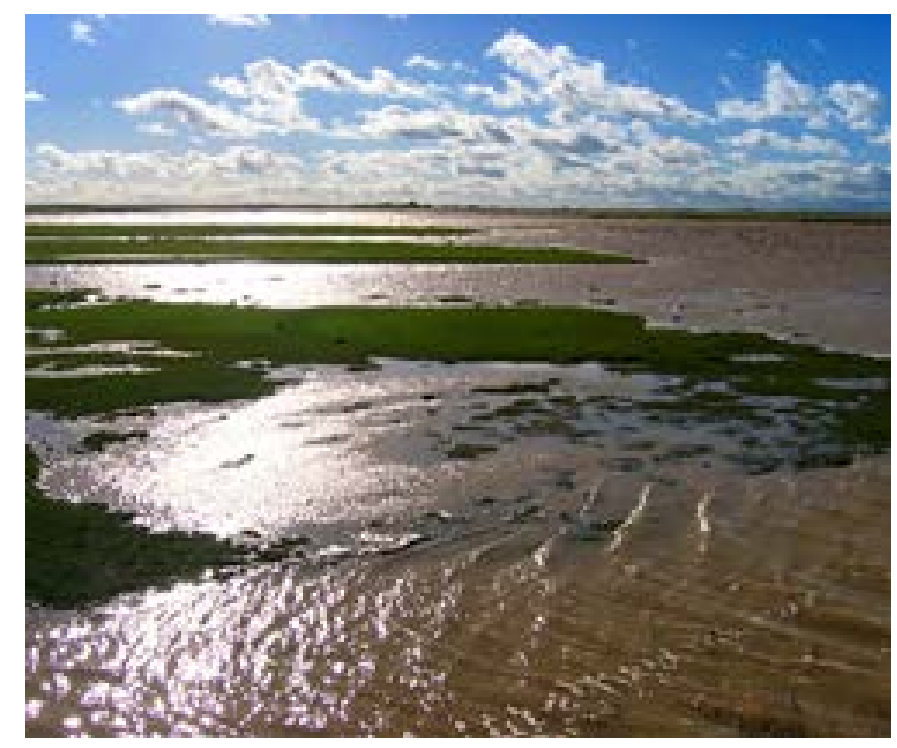

Laguna Grande Villafáfila, Zamora 2006 | foto Guillén Pérez

\section{BIBLIOGRAFÍA}

- ENCUESTA de ocupación en alojamientos de turismo rural 2015. Instituto Nacional de Estadística, 2016 <www.ine.es> (INEbase/Encuesta de Ocupación en Alojamientos de Turismo Rural/ Encuesta de ocupación en alojamientos de turismo rural 2015) [Consulta: 22/02/2017]

- MOLINA DE LA TORRE, I. (2012) Evolución y principios para una política de ordenación territorial en las áreas rurales de Castilla y León. Valladolid: Fundación Perspectivas de Castilla y León, 2012

- PLAN estadístico de Castilla y León 2014-2017 Indicadores Demográficos 2015. Datos provisionales. Estadística de Castilla y León. Valladolid: Junta de Castilla y León, Consejería de Economía y Hacienda, 2016 <http://www.jcyl.es/web/ jcyl/Estadistica/es/Plantilla100/1284159001552/124698 9275272/__> [Consulta: 22/02/2017]

- PRograma de Desarrollo Rural de Castilla y León 20142020. Valladolid: Junta de Castilla y León, Consejería de Agricultura y Ganadería, 2014

- ROJAS RABANEDA, A. (2011) Herramientas y estrategias de difusión del Patrimonio Histórico: los eventos de recreación histórica en Cataluña. e-rph Revista electrónica de patrimonio histórico, 9, Universidad de Granada, 2011 <http://www. revistadepatrimonio.es/revistas/numero9/difusion/estudios/ articulo.php> [Consulta: 22/02/2017]

- RUIZ EZQUERRO, J. J. (1991) Etnografía soriana; museos etnográficos rurales. Soria: Diputación de Soria, 1991 